\title{
Aportes de la filosofía analítica a la construcción de sentido sobre el lenguaje religioso"
}

\author{
Estiven Valencia Marín**
}

Recepción: 23 de septiembre de 2019 • Aprobación: 20 de octubre de 2019

\section{Resumen}

El esfuerzo humano por la búsqueda del sentido de la existencia se inscribe en la práctica discursiva que las religiones exhiben no solo de la situación existencial del hombre, sino también de la experiencia de este con lo trascendente. De hecho, un lenguaje que expresa lo trascendente es básicamente intuitivo, sin embargo, la idea de carencia de significado para los contenidos de fe aconteció por boca de filósofos analíticos. De ahí que el presente artículo intente reproducir algunas consideraciones pro et contra de los contenidos de fe por parte de pensadores adscritos a la escuela analítica, para luego enfatizar en una necesaria contribución de la filosofía en el tratamiento del lenguaje religioso.

Palabras clave: lenguaje religioso, metafísica, sentido religioso, filosofía analítica, positivismo lógico.

* Artículo de investigación resultado del proyecto de fundamentación de la línea de investigación Filosofía y Religión, ejecutado en la Universidad Católica de Pereira. Citar como: Valencia, E. (2020). Aportes de la filosofía analítica a la construcción de sentido sobre lenguaje religioso. Albertus Magnus, XI(1), 93-112. https://doi.org/10.15332/25005413/6196

* Universidad Católica de Pereira, Pereira, Colombia. orcid: https://orcid.org/0000-00019652-7701. Correo electrónico: steven01051991@hotmail.com 


\title{
Contributions of analytical philosophy to the construction of meaning on religious language
}

\begin{abstract}
The human effort in the search for the meaning of existence resides in the discursive practice that religions exhibit not only of the existential situation of man, but also in his experience with the transcendent. In fact, a language that expresses the transcendent is basically intuitive; however, the idea of lack of meaning for the contents of faith came about by word of analytical philosophers. Hence, this article attempts to reproduce some considerations pro et contra of the contents of faith by thinkers linked to the analytical school, to then emphasize a necessary contribution of philosophy in the treatment of religious language.

Keywords: religious language, metaphysics, religious meaning, analytic philosophy, logical positivism.
\end{abstract}

\section{Contribuições da filosofia analítica para a construção do significado na linguagem religiosa}

\section{Resumo}

O esforço humano pela busca do significado da existência faz parte da prática discursiva que as religiões exibem não apenas da situação existencial do homem, mas também da sua experiência com o transcendente. De fato, uma linguagem que expressa o transcendente é basicamente intuitiva; no entanto, a ideia de falta de sentido para o conteúdo da fé veio da boca dos filósofos analíticos. Portanto, este artigo tenta reproduzir algumas considerações a favor e contra o conteúdo da fé de pensadores ligados à escola analítica e, em seguida, enfatiza uma contribuição necessária da filosofia no tratamento da linguagem religiosa.

Palavras-chave: linguagem religiosa, metafísica, filosofia analítica, positivismo lógico, sentido religioso. 
El carácter paradójicamente racionalista de las creencias religiosas, se funda en la certeza de no incongruencia entre su credo y el razonamiento

(BochensKi, Lógica de la Religión)

Una cuestión religiosa es solo o cuestión de vida, o palabrería vacía. Tal juego de lenguaje - puede decirse - solo se hace con asuntos de vida

(Wittgenstein, Diarios 1930-1932)

\section{Introducción}

Abundantes son las cuestiones que la filosofía y la misma ciencia han efectuado al discurso religioso en la historia, cuestiones tales que, desde un punto de vista lógico y conceptual, detentan el análisis de un discurso simbólicamente caracterizado por representaciones que los hombres se hacen de lo sagrado, de lo divino, de Dios. De modo que, durante las últimas dos centurias, la inclusión de objetos de estudio a las ya existentes corrientes del saber: la filosofía analítica y la filosofía de la religión, para las cuales el hecho religioso fue materia de sus reflexiones, ora para crítica, ora para justificación de este, revela un desarrollo investigativo sustancial en cuanto a posibles relaciones entre conocimiento y creencia. Indagar, entonces, las posibles relaciones entre ambas esferas, en el marco de una discusión sobre el sentido de lo religioso, sienta las bases de una reflexión sobre el valor de la fe, de la religión.

Dicho sea de paso, la experiencia del sentido es aquella que los hombres, a través de los tiempos y en cualquier cultura, tienen como objeto para conducir acciones y cuestiones que emergen de situaciones propicias o adversas, situaciones tales que hacen parte del mundo circundante. De manera que el esfuerzo humano por la búsqueda del sentido de la existencia, del sentido que otorga toda contestación a las inquietudes a los problemas vitales que intenta subsanar el ser humano, tras la evocación de su condición limitada y finita, hacen parte del hecho religioso sin ser este su único fundamento. Así pues, toda consideración de carácter ideológico, dogmático o cosmogónico que denote algún sentido, supone prácticas discursivas que en las religiones expresan acerca de la situación existencial del ser humano y de la experiencia con lo trascendente. 
En términos generales, un lenguaje que expresa lo divino, lo trascendente, por tanto, lenguaje religioso - a merced de la acción mutua de estímulos y disposiciones naturales por las cuales los seres humanos gestan interpretaciones del mundo y sentimientos-, aparece como básicamente intuitivo. Carácter intuitivo por ser aprehensión de un objeto de pensamiento con cualidades sublimes, cualidades otorgadas a causa del poder semántico (semantic power) de los conceptos teológicos, según el metafísico Ferré (1961, p. 154), y la natural predisposición al conocimiento de lo santo, según Otto (2001, p. 217). No obstante, el progreso de una idea de carencia de significado y de valor, declarada por las corrientes de pensamiento adversas a una justificación para los contenidos de índole religiosa, aconteció en réplicas ulteriores bajo consideración de teólogos y filósofos analíticos.

Las críticas del Círculo de Viena y el positivismo inglés inician, por una parte, la negación de cualquier posibilidad de alcanzar el conocimiento a través de contenidos religiosos, y, por otra, la simplificación de dicho lenguaje de fe a valores solo expresivos y emotivos. Tal es el asunto de figuras como el filósofo británico Ayer y el analista Nielsen, siendo este último legatario del evidencialismo, ponderado por el positivismo lógico al exonerar a la religión de verdad, debido a la privación de realidad física que confirme sus juicios para ser comprendidos (Nielsen, 1982, p. 132); aunque el positivismo que aquí se indica extrema la prueba empírica, por lo cual, según Ayer, toda intuición es inútil como prueba de la validez de una proposición (1984, p. 129). Dicho así, un esfuerzo por justificar la fe acoplada a una comprensión intuitiva, lejos de una constatación fáctica, implica para esta su expulsión del campo del conocimiento.

Posiciones semejantes a una epistemología empirista, que aboga por los hechos como fuente de saberes, son las denunciadas por el crítico norteamericano Ferré, al reprobar aquella carencia de sentido lingüístico de las declaraciones religiosas apoyadas por netos positivistas, para lo cual el discurso teológico-religioso que reclama significación tiene en las expresiones de emotividad su funcionalidad y consistencia (Antiseri, 1976, p. 37), aunque la verdad apunta únicamente a proposiciones con objeto tangible. Bajo esta denominación de correspondencia verdad-hechos, el proyecto de justificar la creencia en Dios resulta errada (misguided) porque, al decir de Phillips — portavoz canadiense del posible asidero de la filosofía de la religión en el saber wittgensteiniano - creer en Dios es inteligible y aceptable (intelligible and acceptable) en sus propios términos, sui generis (Davies, 1993, p. 11).

Inteligibilidad y aceptabilidad de la creencia particular en Dios, lejos de ser un asunto de comprobación de significado factual cuya verdad recae en 
experiencia que le afirme, tiene en la descripción religiosa del mundo y sus acontecimientos la forma de proceder que sucede como status vitæ. Tal es la razón por la que, ante la multiplicidad de formas para comprender, estimar o juzgar todo cuanto acontece al hombre, las creencias constituyen sentidos de lo real en tanto nociones sobre diversos aspectos de la vida humana, que no tienen en la justificación exterior su criterio de acción, sino en la confianza que el creyente otorga a su fe. Así, la estima cognoscitiva de los contenidos de fe, además de la coherencia semántica, deviene en temática como aspecto interpretativo de la experiencia del hombre para una producción analítica que hace frente a la crítica de los neopositivistas.

La obra analítica y teológica del inglés Hick señala la carencia de un término lógico capaz de anular o reducir al sin sentido a toda aserción de fe; fe plausible de confirmación en la práctica cotidiana del hombre, esto es, la moral. En efecto, el sentido del lenguaje religioso cristiano está en posibilidad de una verificación a raíz de los contenidos mismos de fe, puesto que la incarnatione Verbi y, por demás, la parusia Christi, aseguran la presencia o realización de los atributos divinos, facticidad dada en la figura de Cristo (Antiseri, 1976, p. 137) que viene, en últimas, a conminar el sinsentido del discurso religioso por causa de una experiencia cierta de Dios. Pero también, la idea de descubrir una presencia divina mientras la mera interacción del hombre con el mundo se efectúa, es el acceso a un conocimiento de Dios previsto por el renombrado inductivismo tomista.

Es el creyente quien realiza un descubrimiento (discovery) de la inmanencia de Dios en el mundo por medio de la intuición que el hombre tiene de las cosas creadas, proceso por el que el profesor californiano Kellenberger hace de la religión un instrumento de saber (religious knowledge), sin que esto signifique un conocimiento directo de Dios, de Dios en sí mismo (1985, p. 186). Por lo demás, para las actuaciones que se desprenden por acto de fe y su contenido, resulta innecesario el criterio de verificación en sus proposiciones, aún si existiesen pruebas para comprobar cuanto dicen los dogmas. Bien vistas las cosas, un asunto importante para la posterior generación de filósofos analíticos y lingüistas es la distinción de referencia y sentido en los significados de los conceptos, aspectos que surcaron el problema del sentido (Sinn) y sinsentido (Unsinn) del lenguaje religioso.

La importancia que se concede al análisis del lenguaje, y la certeza de los positivistas en abolir la mayoría de los problemas filosóficos dadas las limitaciones del lenguaje, cuyo predio de conceptos ambiguos se tornan impropios para una investigación científica, tiene por objeto ajustar los criterios con los cuales una proposición se dice con sentido. Precisamente, esto es lo que oferta el 
pensamiento temprano de Wittgenstein, que aboga por una estricta descripción de la realidad, descripción de estados de cosas posibles contra proposiciones que se alejan de los elementos del mundo capaces de dar razón de este, de ahí el sinsentido menospreciado en el Tractatus (1.2; 2.01). Y aunque dicha logicidad fue aplicada de modo sumamente crítico a las ideas de carácter religioso por pensadores posteriores al ya citado autor austriaco, tuvo su comienzo en los escritos de Frege y el británico Russel.

Con todo el panorama descrito respecto del debate por el sentido o el sinsentido del lenguaje religioso, el presente estudio propende describir el despliegue histórico de una teoría del lenguaje en la sapientia cristianæ, como claro precedente del problema moderno sobre el sentido del discurso de fe, y descifrar posibles aportes de la filosofía analítica, de una filosofía del lenguaje, al discurso religioso en la exploración de precisiones lógicas, pese a las severas críticas hacia este. Para ello, se recurre a una sucinta exposición de conceptos y nociones relacionados con el discurso religioso en la historia del cristianismo, luego se reproducirán algunas consideraciones pro et contra del hecho religioso por parte de algunos pensadores vinculados a la escuela analítica, para, finalmente, puntualizar en la necesaria contribución de la filosofía, particularmente analítica, en el tratamiento del lenguaje religioso.

\section{El lenguaje religioso como problemática histórica}

El hombre se muestra en el mundo como un sujeto dado a lo sensorial, afectivo y cognitivo, dimensiones tales adheridas a la pluralidad de estímulos que el medio le proporciona, más la presencia de lo otro semejante, esto es: los seres humanos con los que se construye comunidad, sociedades, una propiedad de su condición relacional. Dichos rasgos, definidos en términos biológicos y relacionales, se imponen como formas de actuación ceñidas también a las circunstancias adversas o favorables con que se presenta el mundo, por las que el hombre experimenta en su existencia diferentes grados de infortunio, ventura y trascendencia. Entonces, un afán natural por remediar limitaciones que aquejan al hombre o, por el contrario, por preservar estados de complacencia - la pretensión de expresar o develar a otros la experiencia existencial-, supone, de antemano, una comprensión de cuanto ocurre en el mundo.

Por tal razón, el lenguaje perfila ser un modo de estar y actuar en el mundo, que hace de los sujetos agentes de comprensión y posesión de lo real, en tanto que todos los aconteceres de este son aprehendidos por el ser humano bajo el uso 
del concepto o definición dado en el lenguaje por antonomasia. Mas en el ámbito cristiano, la relación palabra-teología es la que adquiere un tajante acercamiento a los problemas lingüísticos, si bien la trascendencia tanto de los discursos escritos como los orales de la revelación cristiana obliga, por necesidad de comprensión, a una interpretación semántica de las palabras. Es así como el discurso de la doctrina y los textos sagrados recalan en una discusión primigenia sobre el significado de sus múltiples expresiones, siendo objeto de estudio en la reflexión de algunos Patres Ecclesiarum, la lógica formal de la escolástica y la hermenéutica bíblica del siglo XIX.

En primer lugar, la trascendencia o los estados inefables que el hombre experimenta en relación con lo sagrado no alcanza a comprenderse por la vía del lenguaje ordinario, discurso descriptivo o científico; sin embargo, el desvelamiento simbólico que se extiende plus ultra de objetos concretos da forma a las experiencias referidas. Lo que aquí se observa es la elaboración de una teoría de los signos que resulta determinante en la sacramentología de los escolásticos ${ }^{1}$, por la que el léxico teológico aduce una comunicación de bienes divinos, léxico que excede a las ocasiones probatorias empíricas tenidas por científicas. Empero, semejante pretensión religiosa, empeño o inquietud natural por escrutar allende lo puramente material - dispuesta sin más por un deseo de sapientia Dei, según Agustín de Hipona-, se resuelve por la formación de representaciones a merced de ideas a priori de dónde se engendró, al decir de Otto (2001, p. 153).

Independientemente de concluirse un conocimiento de lo trascendente, de lo divino, de lo eterno, cierto es que los usuales enunciados respecto de este, que suelen definirse como atributos de Dios, sugieren un saber real que abarca lo

1 En los primeros cuatro siglos del cristianismo, los pensadores del tiempo, a quienes comúnmente se les conoce como padres eclesiásticos, dadas sus reflexiones de importancia para el desarrollo del pensamiento y la teología cristiana, no trataron los sacramentos de modo tan amplio ni con terminología adaptada para este propósito, tal como los expusieron teólogos y escritores cristianos del periodo escolástico. De modo que el monje toursiense Berengario, adscrito a la escuela chartrense y precursor de la consubstanciación eucarística; el filósofo Pierre Abélard, tratadista de la reconciliación a partir de su pensamiento moral; el teólogo Hugo, perteneciente a la abadía parisiense de San Víctor, autor de Sacramentis Legis Naturalis et Scriptæ y Sacramentis Christianæ Fidei; el novarense Pedro Lombardo, el obispo autor de los Libri Quattuor Sententiarum, que en su libro IV compila un tratado general sobre sacramentos; y el monje benedictino Tomás de Aquino, quien en la tercera parte de su Summa Theologiæ se ocupa de lo sacramental, contribuyeron a la construcción de una doctrina sacramental como tratado autónomo. Sin embargo, dicha autonomía disciplinar fue alcanzada por completo en las reflexiones del Concilio de Trento. Un desarrollo doctrinal de los sacramentos puede consultarse en el Tratado General de los Sacramentos, de Ramón Arnau (1994), la Teología Fundamental de los Sacramentos, de José Cristo Rey (1994), o la Teología de los Sacramentos, de Herbert Vorgrimler (1989). 
supramundano, saber manifiesto en el simbolismo de la palabra según advierte Rahner (Grabner, 1976, p. 250). Cabe señalar, entonces, que la experiencia del ser humano con lo perenne, lo extramundano, acaba siendo un hallazgo o descubrimiento de posibles realidades a las que se accede por lenguaje simbólico, lenguaje que se acomoda a sentidos que se quieren expresar, aunque inenarrables, a partir de exclusivos enunciados racionales. Desde esta óptica, el contenido de textos sagrados y expresiones sobre lo dicho por atributos divinos, que en autores eclesiásticos parecen reflejo de un conocimiento de Dios a través de signos, no dicen realidad en sí, pues, según Maceiras:

[...] a través del proceso de intensificación y sobrepasamiento que manifiestan las expresiones límite [...] organizan por proclamación extravagante al común sentido algo imposible de decir, que guarece a Dios como realidad inadecuada para ser dicha en cualquier lenguaje. Esas expresiones introducen experiencias límite que difieren de la experiencia ordinaria [...] Y aunque las expresiones límite refieren a lo que no se puede decir, Dios no está exento de los modelos por los que es nombrado. (citado en Fraijó, 1994, p. 690)

Dichos contenidos de fe - que no enuncian el carácter concreto de la perfección divina - ni los instrumentos que describen la infinita naturaleza de la deidad, se perfilan como analogía, como recurso lingüístico que acomode términos con el fin de hacer comprensible tales experiencias que se tienen de Dios. En otras palabras, la doctrina de la analogía solo indica la ilación entre los diferentes significados de una palabra que intenta narrar, convenientemente, toda experiencia mística, la experiencia de lo trascendente; esto es, para el filósofo estadounidense Hick (1990, p. 84), una manera de explicar los términos de lo divino (terms of the Deity) cuya existencia se admite. Acontece, entonces, con la analogía, un marco de referencias limitadas acerca de Dios, referencias tales que evocan el sentido del misterio divino tan característico de la confesión judeo-cristiana, y cuya grave aceptación se dio en la escolástica, de sobremanera en Tomás de Aquino.

En aquel entonces, las expresiones de fe ajustadas a los divinis nominubus, asistieron a la elaboración de un examen sobre el lenguaje teológico, escrutinio cuyo rumbo crítico adaptó la tradición precedente a la escolástica, con ocasión de departir respecto de Dios sin que ello implique equiparar a este con los objetos del mundo. A causa de ello, un interés por el estudio del patrimonio discursivo de la teología cristiana incrementó el número de eruditos a finales de la escolástica, consolidando un método para la aprehensión de significaciones que sugieren la 
existencia y el conocimiento de lo divino. Tales consecuencias tienen como tratamiento esencial la utilización de modelos lógicos y epistemológicos aristotélicos, tratamiento que - desarrollado por Pierre Abelard, el escocés Duns Scoto, el inglés Ockham y Tomas de Erfurt, entre otros - adquiere posteriormente otro sentido.

Se dice otro tanto relativo a la crisis de la conciencia religiosa entrada la modernidad, en la que acción y pensamiento cristianos se ausentan del ámbito de la razón, acción y pensar que perfiló ser en la antigüedad el principio que explica la totalidad de los hechos del mundo, así como las hazañas humanas a través de la voluntad divina. Este es el saldo que todo ingenio teológico sufraga por su limitada aplicación a la vida, es decir, la sujeción de la fe a la sola dimensión práctica sin que tenga objeto concreto que le sustente; uso del lenguaje religioso que no busca realidad empírica por el contraste de experiencia sensible y metafísica (Grabner, 1976, p. 194). Con esta orientación kantiana, la interpretación de textos consigue preeminencia ante la necesidad de escudriñar las raíces de la doctrina cristiana, validez en perspectiva diacrónica por la carencia de referente fáctico que legitime el contenido de esta.

El progreso de los estudios en literatura hebraica, el avance en la explicación de los conceptos semíticos y de otras lenguas en que se inscribe la tradición judeocristiana, forman toda una investigación de carácter histórico, que brinda nuevas visiones para dilucidar los sentidos que subyacen a las muchas expresiones dogmáticas de la fe. Tras la emersión de una crítica histórica y literaria, la exégesis incursiona como molde de ciencia e investigación para el estudio pormenorizado de los estimados textos sagrados, estudio que para teólogos actuales no es solo una cuestión metafísica del discurso religioso, sino, también, de crítica ideológica y social que, en sentido general, influye sobre la producción de dicho lenguaje ${ }^{2}$. En relación con esto, las posiciones críticas que hacen del mensaje religioso algo

2 La crítica ideológica y social que aquí se indica, refiere al estudio de las influencias que ejerce el ámbito social en lo religioso y viceversa. Bajo este presupuesto, del que se desprende el contenido sociológico de la religión, reconocer el hecho religioso como fenómeno social, cultural y colectivo tuvo sus inicios en las consideraciones de pensadores como el francés Durkheim (1912) y el alemán Weber (1921). Para este, los compromisos y supuestos que aparecen como inevitables en un orden social tienen, en la relación política y religión, el punto álgido de su desarrollo, el cual involucra una ética de fraternidad funcional, según expone en su obra Sociología de la Religión. Por su parte, en Formas Elementales de la Vida Religiosa, Durkheim hace de los conceptos e ideologías, representaciones colectivas que ponen en juego las condiciones fundamentales del entendimiento entre espíritus y la estabilidad social. Situación semejante es la que concibe el filósofo lógico Bochenski (1967), fraile dominico, quien en su Lógica de la Religión hace de lo religioso parte de un complejo de acontecimientos que se presentan en grupos humanos, sucesos que, sin más, determinan conductas comunes de los miembros de 
cuestionable, no acortan el reparo del sin sentido para la religión, reparo que se da, según Velásquez, porque

[...] sobre la base del principio de verificación sólo las proposiciones dotadas de significado cognitivo son las de las ciencias naturales (verdaderas o falsas), cuyo significado es comprobado o verificado experimentalmente. No acontece lo mismo con las proposiciones de la lógica (tautologías o contradicciones) o de las matemáticas, ni con las de la filosofía, metafísica y teología, contenidos imposibles de someter a la experiencia. Por tanto, estas dos clases, adolecen de sentido conforme a los positivistas. (citado por Fraijó, 1993, p. 536)

De manera que esa tesis positivista, tesis que sospecha de toda moción teológica y somete la filosofía a simple análisis de lenguaje, con el propósito de distinguir las expresiones con significado, es producto de empirismo exacerbado propio del logicismo del Wiener Kreis (Círculo de Viena) que se ampara en el progreso científico. Pero es tal empirismo de moderna promulgación, que tiene por finalidad favorecer el análisis de los enunciados, un inexorable contrasentido respecto de la valoración del empirismo que desecha el conocimiento analítico para toda experiencia, según Hempel (citado por Ayer, 1965, p. 115). A fin de cuentas, cualquier proposición que advierta apriorismo o que apropie como fin una descripción o representación de hechos posibles, resulta falsable, por cuanto el sentido de los enunciados está condicionado por la verificación como factor esencial de verdad (Ayer, 1965, p. 246).

Por tal opinión, los enunciados no tautológicos correspondientes a los de la lógica y la matemática, paralelos a los enunciados inverificables por experiencia sensorial, adolecen de sentido, condición ontológica materialista característica de la visión analítica, que despoja al lenguaje religioso de capacidad significativa y valor cognoscitivo. $\mathrm{Y}$ pese a que las sentencias de talante teológico traen consigo la devaluación de sus contenidos textuales y predicaciones de Dios, a causa del movimiento neopositivista descrito, una respuesta de cara a las negativas del verificacionismo del Círculo de Viena no se hizo esperar. He aquí, pues, el esfuerzo inicial por situar la fe en los cánones de la razón, es decir, lejos de la superstición y recio dogmatismo acrítico o fixista, con la interpretación simbólica y diacrónica

una comunidad, por ende, la religión es fenómeno social. Alusiones al tema desde comienzos de siglo están en los sociólogos Niklas Luhman (2007) y Frédéric Lenoir (2005). 
de los contenidos de fe, tal como se ha narrado, y posterior defensa de la capacidad significativa de aquella.

Es preciso notar que la significatividad del lenguaje religioso entra en consideración, desde una óptica analítica, posterior al asentamiento de la pragmática lingüística y el progreso de los juegos de lenguaje del pos-Tractatus wittgensteiniano, ocasión propicia para intentar reivindicar el valor cognoscitivo de las proposiciones religiosas. Con esta idea previa se llega a la recepción de viabilidad de la creencia en Dios, razón por la que autores como el filósofo británico Brian Davies manifiestan la extraña experiencia de Dios al no ser corpórea, por acto de conciencia no inferencial (non-inferencial act of awareness) (1993, p. 130). A partir de una razón como la expuesta, algunos teólogos reclaman el carácter racional de la fe, carácter que refleja, al decir de Hick, un conocimiento de uso práctico (practical use), a pesar de ser una experiencia sin prueba empírica que pueda representarle (1966, p. 208).

En resumidas cuentas, la teología que tiene en el discurso religioso su materia escrita y vocal para expresar posibles conocimientos acerca de Dios, ante el impacto ora positivo de las nuevas escuelas de pensamiento - como filosofía de la religión y hermenéutica bíblica-, ora negativo por causa de críticas de otras corrientes - como el positivismo lógico y/o cientificismo- aquí expuestos, se hace un asunto en busca de sentido para ser entendido. Empero, aquella disposición empírica, verificacionista u objetual tan reticente - con el perseguido sentido de la fe por parte del neopositivismo que concierne al presente texto-, corresponde preliminarmente a los esfuerzos teóricos desarrollados por los alemanes Gottlob Frege y Wittgenstein, además del británico Bertrand Russell, de quienes se pueden extraer importantes aportes sobre el status logicus de las declaraciones religiosas de los contenidos de la fe.

\section{Consideraciones analíticas sobre el lenguaje religioso}

El razonamiento formal, razonamiento que se caracteriza por el correcto uso de reglas lógicas en su estructura, excede los lenguajes que agrupan saberes concretos de la condición humana, los cuales son conato explicativo de múltiples acontecimientos y problemáticas presentes en el escenario del mundo. A este propósito, se une el proyecto de construcción de un lenguaje que busca en la gramática lógica establecer criterios de verdad y falsedad, criterios que, desde la 
sintaxis y semántica de cualquier enunciado, dependen de una exactitud lógica que ofrece lo que es verificable empíricamente. Esta estimación neopositivista, que participa del apogeo de la ciencia y logicismo que dan por supuesto la inteligibilidad de la realidad y las leyes que la determinan, desplaza, sin medida, a toda enunciación metafísica y religiosa, tenidas por lo más insignificante, puramente emotivo y en nada objetivo.

Precisamente, un proyecto de lógica aplicado al lenguaje para captar la forma precisa en que se construyen proposiciones fue el artificio de Frege, quien emuló la gramática simple de las fórmulas aritméticas con el objetivo de aunar estas al lenguaje natural, a través de signos que cumplen un rol sintáctico ad intra de toda argumentación. En eso consiste formalizar las enunciaciones del lenguaje natural, formalización cuyo contenido matemático señala la no ambigüedad en la exposición de sus razonamientos, adaptando a ellos los símbolos de función algorítmica, que tienen en la eliminación de imprecisiones para el lenguaje común su único interés. No obstante, el rigor de las demostraciones lógicas que supone de axiomas y reglas únicas para toda proposición, contra la existencia de anfibologías que deben evitarse, se aparta del asentimiento único a los juicios verificables empíricamente.

En este orden de ideas, un claro resurgimiento del interés por la lógica para la nueva colocación de una filosofía del lenguaje, interés oculto tras los vastos tratados en la Baja Edad Media, pone en jaque la postura empirista al incluir en la aritmética ámbitos no empíricos, reglas o leyes que sobrepasan los hechos particulares (Frege, 1998, p. 275), idea que abjura de la visión verificacionista de herencia comtiana, como visión señera con acuciante atención tan apoyada póstumamente por el Logischer Empirismus vienés. Así pues, esas leyes universales aisladas de experiencia alguna, leyes que dicen verdad sea de figuras, de oración, de representación y pensamiento, por tratarse de elementos que protestan por necesidad a impresiones de carácter sensible, se convierten en motivo para una distinción entre expresiones cuya certeza depende de pruebas puramente lógicas y otras de hechos empíricos (Frege, 1998, pp. 88-91).

Al interior de dicha distinción de expresiones, aquellas proposiciones o creencias de las que su verdad se dice cuando existen hechos que las refieren, hacen de la correspondencia entre enunciado y hecho un requisito de su certeza. Semejante idea - que apoya el coetáneo de Frege, el matemático y lógico inglés Russell - en los términos de construcción de enunciados convenientemente garantizados, de modo que su verdad se conserva reduciendo al mínimo un número de entidades no observadas (1966, p. 465), difiere de la emitida por el pensador alemán, para quien la verdad no es una propiedad que responde a impresiones 
sensoriales y se excluye de las cosas capaces de ser percibidas sensorialmente (Frege, 1998, p. 200). De ello se colige la reticencia frente aserciones de cuño metafísico-religioso, que no pueden ser ratificadas por correspondencia a facticidades; sin embargo, aun así, esta tendencia alcanza nuevos matices:

El empirismo en religión no ha tenido su audiencia decisiva [...] Figurémonos que ciertos eventos extraordinarios de repente e inexplicablemente comienzan a ocurrir [...] Figurémonos además que esto sucede incluso cuando gente tiene enfermedades que los médicos creen bastante incurables. Aquellos que poseen fe, es decir, aquellos que creen en Dios y le piden ayuda a Él, mejoran [...] Si hubiese áreas en nuestra experiencia que no admite una aclaración naturalista, ¿no sería esto una forma de confirmar las creencias teístas, y dudar o desgastar al menos las naturalistas? (Nielsen, 1982, pp. 171-172)

Para este tipo de circunstancias, existen consideraciones de autores contemporáneos que respaldan la posibilidad cognoscitiva de la fe, a expensas de las renuentes críticas logicista y empirista de pensadores que acatan el principio verificacionista para enunciados acerca del mundo y sus fenómenos, y de las cuales el neopositivismo es su legatario. Este es el punto en que dicho principio aplicado como sentido del lenguaje, posición en la que aparece Russell y algunos representantes del Círculo de Viena (Wiener Kreis) como sus adalides, se traslada ahora de bando para justificar, desde una óptica empirista las proposiciones de la fe. Distinto al pertinaz juicio de insignificancia para contenidos religiosos, el citado teólogo inglés Hick, el británico Ramsey, el filósofo estadounidense Kellenberger,

3 La injerencia de estimadas experiencias de fe como las que el profesor de filosofía Nielsen aquí expone, hace las veces de ejemplo para cierto tipo de acontecimientos que personas del común, por lo inusuales e inenarrables, denominan milagros. Sin embargo, la mención a estos sucesos por parte del canadiense citado, no le hace un defensor de las tesis teológicas, pues, aunque estudioso del fenómeno religioso, fue un precursor del ateísmo contemporáneo. Obras tales como Atheism and Philosophy (2005), Naturalism and Religion (2001), Ethics without God (1990), Contemporary Critiques of Religion (1971), entre otras, presentan una serie de críticas a la perspectiva gnoseológica que autores cristianos sostienen de toda enunciación teológica. El fragmento anterior, tomado de An Introduction to the Philosophy of Religion (1982, pp. 171-72), reza así: "Empiricism in religion has not had its final hearing [...] Suppose certain very extraordinary events suddenly and inexplicably began ocurring [...] Suppose further that this happens even when people have disease that doctors believe are quite incurable. Those who hace faith, that is those who can really bring themselves to believe in God, get well [...] If there were areas in our experience which did not in fact admit of naturalistic explanation, would this not go some way to confirm theistic beliefs and disconfirm or at least weaken naturalistic ones?". La traducción de este fragmento, y otros tomados en lengua inglesa para el presente escrito, son de nuestra autoría. 
entre otros, sugieren la racionalidad de las creencias a partir de evidencias que las validan.

Así, todo sentido presto a las experiencias humanas constituye un modo por el que el ser humano entra en relación con el mundo próximo, sentido del que dispone el pensamiento y la conducta de todo hombre como factor determinante a la hora de constituirse la personalidad de este. No en vano, ante los múltiples acontecimientos que experimentan las personas, las actitudes de aceptación o rechazo aparecen condicionadas, de antemano, por interpretaciones que recrean a modo de juicios lo percibido o pensado, empero, los elementos que hacen parte de estas no se limitan a objetos físicos, sino también a entidades no materiales. Por ello, tanto los fenómenos del mundo como los eventos psicológicos de los sujetos acaban en una significación situacional (situational significance), esto es, la interpretación por vía de acciones o conceptos de la complejidad que es el mundo (Hick, 1966, p. 101).

De la complejidad del mundo, del contemplar cuanto existe en él y experimentarlo, el hombre, a través de las cosas creadas, otorga causalidad a estas; causa cuyo modo metafísico se superpone al carácter factual de lo percibido en un proceso de abstracción formal, por el cual su determinación existencial está dada en algo extrínseco a la cosa misma. Se acude aquí al descubrimiento de la presencia de Dios a partir de lo ente, de la cosa o ser que en su perfecta constitución denota un artífice del cual procede, suceso que, en opinión de James Kellenberger, hace del mundo un lugar idóneo para percatarse de lo religioso (religious discovery) (1985, p. 131). Esta moción descubre un rasgo interpretativo de la realidad, interpretación o significación superior cercada por una libertad cognitiva (cognitive freedom), sea por recusar o admitir lo trascendente, lo divino, según advierte Hick (1990, p. 65).

Lo característico de la creencia religiosa es que sitúa la vida del creyente en un estilo de referencia con respecto al mundo circundante y cuanto en él sucede, sin embargo, la alusión a sus componentes y su ordenada colocación en el mundo se muestran insuficientes para declarar un evidencialismo empírico de que lo que se dice es divino, trascendente. De cara a esta posición, la resolución wittgensteiniana de irracionalidad señala el cuño inverificable de las enunciaciones de fe, es decir, la no necesidad de pruebas o evidencias para ser aceptadas, sin que por ello un seguimiento de creencias sea un asunto estulto (Wittgenstein, 1992, p. 13). $Y$ aunque las creencias religiosas no se reducen a ejercicio racional, si bien la tradicional analogía para referirse a lo divino depende, sin más, de un proceso de 
razonamiento a partir de asociaciones, su certeza la da una seguridad subjetiva y no el objetivismo universalista que ostenta la ciencia:

De la seguridad, de la creencia quisiéramos decir que son tono de pensamiento y es verdad: tienen una expresión en el tono del discurso. Pero no piensen ello como en sentimientos que se dan al hablar o pensar. No preguntes ¿qué ocurre dentro de nosotros cuando estamos seguros de que...? sino ¿cómo se muestra la certeza de que es así en el actuar de la gente? Aunque puedas tener absoluta seguridad sobre el estado anímico del otro, ella sólo es seguridad subjetiva, no objetiva. Tales palabras dicen una enorme distinción entre juegos de lenguaje (sprachspielen). (Wittgenstein, 2009, p. 623)

A dicha seguridad subjetiva (sicherheit subjektive) ${ }^{4}$, seguridad que es una actitud de confianza que hace al individuo emitir juicios acerca del mundo, ora de hechos particulares, ora de acontecimientos que se estiman supra naturales, le es, asimismo, inherente la dimensión práctica, la cual constituye la personalidad de todos los individuos. Dicha practicidad humana, practicidad circunscrita a las acciones que el hombre ejerce con sus semejantes y consigo, ha de acortar el camino despreciativo que los empiristas lógicos y lingüistas cimentaron para las proposiciones religiosas, dado que la moral dota de sentido a estas. Es así como para teólogos y filósofos adversarios a la posición neopositivista, el vital reconocimiento de la religiosidad está en el compromiso que de la contemplación se sigue, contemplación que, al decir Ramsey, se debe a intuiciones profundas sobre el mundo visto (Antiseri, 1976, p. 143).

4 Con seguridad subjetiva (sicherheit subjektive), bajo el discurso del filósofo vienés Ludwig Wittgenstein, se indica el sentimiento de firmeza o certeza que, en primera instancia, condiciona a toda creencia para ser seguida, pero cuyo asentimiento se debe a la disposición individual, es decir, al estado interno del sujeto capaz de aprobar o recusar la misma. No obstante, existe una distinción entre creencia religiosa y cognitiva, creencia cognitiva o conjetura, en tanto eje para el ofrecimiento posterior de pruebas, y la de talante religioso que, necesariamente, refiere a la realización de obras. Con esta precisión, en cuestión de fe, la irracionalidad se caracteriza por el simple hecho de verse libre de pruebas, de verse exenta de descripción, de modo similar a las ciencias que están sometidas a principio de verificación, siendo su certeza supeditada a la prueba, y solo dada a la confianza en lo que se estima digno de seguimiento, tal como hace notar el filósofo Norman Malcolm en su obra Wittgenstein: A Religious Point of View? (1997, p. 20). Ante los intentos de racionalización de la fe, su contrario, el criterio de irracionalidad, fue la base teórica para que pensadores como Karl Barth y Bultmann se esforzaran por recuperar el sentido trascendente de la revelación. Así, el lenguaje humano y la indagación histórica no están en capacidad de ofrecer detalles acerca de Dios, según términos de los textos The Word of God, the Word of Man (1978) y Das Verhältnis der urchristlichen Christusbotschaft zum historischen Jesus (1960) respectivamente. 
Baste lo anterior para asegurar un enfoque no cognitivista de la fe como reclamación de Wittgenstein al principio empirista, que admite por verdad aquello que se basa en datos de los sentidos, y para el cual es lenguaje sin sentido aquel que no es verificable empíricamente. Ahora bien, el discurso religioso asume criterios propios de justificación, criterios peculiares de sentido que son intransferibles a otros tipos de discurso, criterios que prescinden de objetos tangibles y hechos visibles, pues solo los valores existenciales, es decir, aquello que adjudica sentido a la vida y orienta los actos humanos en la bondad, determinan el peso de las creencias religiosas. Entonces, una pragmática del lenguaje religioso que aquí se colige al posicionarse las actuaciones humanas como objeto de las creencias, revela del discurso teológico su perfil funcional, en términos del filósofo estadounidense Ferré (1961, p. 63).

Dicho perfil funcional, que comporta esos enunciados religiosos al denotar no solo acciones por las cuales el hombre ordena su existencia, sino que también aprueba aquello que estima digno de ser seguido, concluye el descrédito de toda experiencia real o posible de las que el rigorismo sintáctico y semántico neopositivista se jacta. Pero tal rigor, tuvo también contestación por parte de lógicos cristianos como Bochenski, para quien existe una engañosa noción en la identificación de los vocablos significado y verificación (1967, p. 104), noción que, vista desde Ayer, imposibilita la significación de conceptos metafísicos por mor de estar fuera de experimentación (1984, p. 141). Se dice, entonces, que ningún enunciado se verifica fuera de su significado, por lo que este último no es idéntico a aquel método, mucho menos pensar que toda verificación se da en la experiencia sensorial.

En general, el señalamiento al significado o sentido de los enunciados de talante teológico como problema que alcanza su apogeo con la aparición de estudios lingüísticos y lógicos tiene como eje de discusión el criterio verificacionista que, para los múltiples autores aquí referidos, es punto pro et contra para justipreciar toda proposición metafísica. De este modo, entonces, los contenidos de fe pueden ser verificados en un marco de referencia en el que se rechazan criterios solamente sensibles, aportación para la construcción de sentido sobre el lenguaje religioso, el cual se vincula con el problema de su cognoscibilidad. 


\section{Consideraciones finales}

El interés por la cuestión de Dios, es decir, el análisis y evaluación no solo de los argumentos de la existencia o cualidades de la naturaleza divina, sino también de la coherencia semántica de los enunciados de fe con el sentido que tales presentan por vía del recurso lógico, sobrelleva grandes cambios a lo largo de la historia. Entre posturas metafísicas propias del Medioevo y la modernidad, y ulteriores tendencias positivistas desarrolladas con la ciencia experimental, se abandonan progresivamente a un modo particular de ver los contenidos de fe para los que un respaldo evidencialista hace de las creencias algo racional. Sin embargo, el auge de estas orientaciones cientificistas cayó en desuso, tras la injerencia de una lógica simbólica capaz de revisar el sentido de las proposiciones religiosas, además de resignificar el sentido de la racionalidad, con el objetivo de valorar las mismas.

De este modo, la inicial hostilidad para con el lenguaje religioso, mítico y metafísico por boca de ciertos filósofos analíticos, tuvo por origen la opinión de carencia de significado, carencia justificada por la falta de criterios de identidad en los contenidos que se enuncian en el dogma, según lo insistentemente expuesto en anteriores apartados. Esta idea - que ampara el iterado defensor del ateísmo contemporáneo, Nielsen - está sujeta a la expresión de sin sentido o de incoherencia, si bien al hablar de Dios se requiere de criterio empírico (empirical criteria) que apropie su existencia (1982, p. 141), es afín al atomismo russelliano. De modo que conocer el mundo está a la base de los elementos particulares que le forman, elementos originariamente materiales - estimados como átomos lógicos y no físicos - que aportan proposiciones con verdad, al corresponder lo percibido con lo posteriormente enunciado.

Las anteriores afirmaciones sugieren a la experiencia sensible como eximio criterio de sentido y de verdad para todo enunciado que pretenda ser objeto de un lenguaje científico unitario, y aunque toda sentencia se dice de un sustrato físico, lo esencial de aquellas reside en el significado que el sujeto pensante concede a estas. En tal sentido, se presume que ni los credos presentan un saber directo de Dios, ni tampoco carecen de significado por no haber criterios de identidad para el mismo, considerando así que toda proposición religiosa, tal como sostiene el ya citado lógico Józef Bocheński, no explica enunciados fácticos, solo de valor (1967, p. 155). Para tales efectos, la no garantía racional de las creencias, esto es, el inconveniente de juzgar estas con estándares de lenguaje científico, se fundamenta en que todo enunciado de fe ofrece una descripción de la realidad con propósito de orientación práctica. 
Semejante visión wittgensteiniana, en términos de Grabner, redunda en la imagen de lo sagrado como evidencia débil que procede de intuición, pero verificada en las consecuencias prácticas que asumen los utilizadores de aquella imagen (1976, p. 224), revalida la idea de verificación tan arraigada en el positivismo. Dicha idea se concebía como anexión de hechos observacionales susceptibles de corroboración empírica, pero ahora fija al objetivo de una justificación racionalista de la fe, la verificación finaliza en un marco de referencias en el que se rechazan criterios solamente sensibles. Particularmente una lógica analógica para conceptos que refieren a Dios, tiene su origen en la experiencia humana, es decir, se aplican cualidades de una cosa en comparación con otra, para aquello que en el hecho teológico se relaciona con conceptos superlativos con el ente divino, al decir de Antiseri (1976, p. 159).

Tal lógica analógica, ajustada a la teología natural, en tanto excluye alguna revelación sobrenatural para descubrir evidencias sobre Dios, concibe las cosas del mundo como el lugar propicio en el que Él se manifiesta, en este caso, como figura de creador, además de confianza en la razón como vía privilegiada para el acceso a lo divino. De modo que, al percibir cuanto en el mundo existe y experimentarlo, el hombre les otorga causalidad, causa cuyo modo metafísico se antepone al carácter factual de lo percibido en un proceso que, como se ha indicado con antelación, es de abstracción formal. A grandes rasgos, todo enunciado al que pretenda pasarse por el filtro de la verificación para acceder a su sentido tiene su soporte en el significado que el mismo ofrece, razón por la cual, dicho criterio se renueva de la versión positivista que pone la verificación en la experiencia sensorial.

Con todo lo dicho, el discurso religioso, como expresión de una estimada experiencia de lo divino, precisa de enunciados cuya forma poética o metafórica se apoya en los haberes de la existencia, sucesos, por demás, inenarrables si basa su proceder explicativo en dichos de talante racional y solo conceptualizadores de la divinidad. Cierto es que una comprensión de lo divino, de lo santo, en palabras del fenomenólogo Otto, entraña predicaciones pensadas por el hombre y atribuibles de manera absoluta y perfecta a Dios, predicaciones logradas por un ejercicio de la razón (2001, p. 145), pero que no se agotan en simples conceptualizaciones. Por este motivo, aunque los conceptos sublimes atribuibles a lo divino intentan describir una experiencia particular de lo santo, la trascendencia de este revela, decisivamente, que el objeto de la religión no es una elemental hechura de la razón humana.

Una vez más, la suprarracionalidad de la fe se manifiesta a expensas de los esfuerzos que muchos autores, verbigracia los expuestos en el presente estudio, 
han hecho con el fin de justificar sus contenidos desde la razón. Esta forma de proceder, que se encuadra dentro de una compresión de la experiencia del creyente, hace suya la posibilidad de hablar de Dios pese a que no se trata de un dato objetivable, como pretende la ciencia y la epistemología modernas al desechar este asunto. No obstante, ante la necesidad de expresar por mediación del lenguaje lo que se experimenta de la fe, buscar esas maneras de hacer comprensible lo religioso demanda prescindir del dogmatismo acrítico que caracteriza a objetos obligados de ser creídos sin su análisis previo.

Análisis y estudio del lenguaje de fe, del lenguaje religioso, es tarea que compete a la teología, si bien tal discurrir lógico no ha estado ausente de todas las reflexiones que desde el periodo patrístico han anunciado particulares modos de hablar de Dios, modos que avisan de límites e implicaciones distintas tanto para el lenguaje común como para el científico. He aquí los motivos por los cuales se expusieron los argumentos de autores adscritos a la corriente analítica, línea de pensamiento que acoge posiciones tanto desfavorables del hecho religioso como flexibles y asertivas para con la noción de significancia de los enunciados teológicos. De hecho, aún se sostiene una discusión sobre las implicancias epistémicas, semánticas y éticas acerca de las creencias de índole religiosa, debido a la insistencia en la temática descrita por parte de la filosofía analítica, la reflexión lingüística, la hermenéutica y otras corrientes.

De todos modos, el énfasis en el análisis lingüístico que la filosofía analítica propone para un estudio sobre el fenómeno religioso y el sentido que subyace a sus enunciaciones, no impone caracteres de racionalidad, como en el caso de ciertos pensadores que abogan por esta idea a propósito de articular conceptualmente las creencias. Es por ello que, para el teólogo y filósofo hispano Fraijó, el intento por captar el significado que los creyentes conceden a todos los contenidos de fe exige el paso de la explicación - como método de conocimiento científico - a la comprensión, en tanto es forma de interpretación de los hechos humanos (1994, p. 70). Todo esto, para dar a entender que el sentido del lenguaje religioso es una cuestión básica y anterior al problema de su valor cognoscitivo, valor para sentencias que, aunque dicen algo del mundo, trascienden a la experiencia sensible que por sí misma no alcanza a comprender. 


\section{Referencias}

Antiseri, D. (1976). El problema del lenguaje religioso. Dios en la filosofía analítica. Ediciones Cristiandad S. A.

Ayer, A. (1965). El positivismo lógico. Fondo de Cultura Económica.

Ayer, A. (1984). Lenguaje, verdad y lógica. Ediciones Orbis S. A.

Bochenski, J. (1967). La lógica de la religión. Editorial Paidós S. A.

Davies, B. (1993). Introduction to the Philosophy Religion. Talking about God. (2a. Ed.). Oxford University Press.

Ferré, F. (1961). Language, Logic and God. The Improper and Proper Functions of the Theological Discourse. Harper \& Row Publishers.

Fraijó, M. (1994). Filosofía de la Religión. Filosofía Analítica de la Religión. Estudios de la Religión y Textos. Editorial Trotta.

Frege, G. (1998). Ensayos de semántica y filosofía de la lógica. Editorial Tecnos S. A.

Grabner-Haider, A. (1976). Semiótica y teología. El lenguaje religioso entre filosofía analítica y hermenéutica. Editorial Verbo Divino.

Hick, J. (1966). The Logic of Christian Faith. En J. Hick, Faith and Knowledge (2a. Ed.) (pp. 151-215). Cornell University Press.

Hick, J. (1990). Philosophy of Religion. (4a. Ed). Pearson.

Kellenberger, J. (1985). Cognitivity of Religion. Three Perspectives. University of California Press.

Nielsen, K. (1982). An Introduction to the Philosophy of Religion. Palgrave Macmillan.

Otto, R. (2001). Lo santo. Lo racional y lo irracional en la idea de Dios. Alianza Editorial.

Russell, B. (1966). Ensayos sobre la lógica y conocimiento (1901-1950). Edición Taurus.

Wittgenstein, L. (1992). Lecciones y conversaciones sobre estética, psicología y religión. Ediciones Paidós.

Wittgenstein, L. (2009). Investigaciones filosóficas sobre la certeza. Editorial Gredos. 